\title{
FUTURE DEMAND FOR \\ SKILLS IN NEW ZEALAND \\ COMPARED WITH \\ FORECASTS FOR SOME \\ WESTERN COUNTRIES: \\ RELATIVE IMPORTANCE OF \\ EXPANSION AND \\ RETIREMENT DEMAND
}

\author{
Department of Labour \\ Wellington
}

Ram SriRamaratnam and Xintao Zhao

\begin{abstract}
Future demand for skills is of considerable interest to policy makers and training providers of many countries, including New Zealand. Occupational employment projection have been implemented in countries such as the US, UK, Canada and Australia. These methods usually take into account growth in GDP of key industries, changes in labour productivity and the long-term changes in the occupational shares of employment by industry. In New Zealand, an assessment of the future prospects for employment by industries and occupations comparable to the overseas approaches has been undertaken over the past few years. These estimates have been used to assess the skills needs in the expanding segments of the labour market. In this paper we compare our forecasts of occupational employment growth with public sector agencies in other countries. The key forecast results of demand for high level skills, for specific broad occupational groups as well as for industry or sector groups for each of these countries as they recover from the economic downturn of varying magnitude and nature are discussed. We focus on both the expansion demand (due to new positions created) and the replacement demand (owing to current positions being required to be filled due to retirement, migration and job mobility) for New Zealand and other countries as applicable.
\end{abstract}

\section{Introduction}

The material covered in this paper commences with a review of the state of play in other countries and in New Zealand, followed by some discussion of the rationale for undertaking occupational (skills) forecasting and the methodology followed by some Developed economies. The latest forecasts available for these countries are then presented at the high level skill categories as well as for some broad occupational and sector groups. Finally, the level of employment growth likely from expansion (from new positions created) is compared with those from retirement and other replacement needs in these countries.

\section{The State of Play in other Countries \& in NZ}

Many countries have developed systems of industry and occupational (or Skills) forecasting. Occupational forecasting is usually described as forecasts of employment by occupations and skill groups.

\section{Scope and Coverage of Occupational Forecasts}

In the US, where such a system has been in operation since the 1950s, the process has evolved over time at the Bureau of Labor Statistics (BLS). The projections presently cover 530 occupations and 50 industries with predictions for over a 10 year period being carried out every other year. The latest predictions are dated December 2009 and cover the 2008-18 period (Woods, 2009).

In the UK, occupational forecasting gathered momentum in the 1980s at the Institute for Employment Research (IER) which uses the comprehensive macroeconomic model of the UK economy operated by Cambridge Econometrics. The focus has been on key industries (67) but fewer occupational groups (25) compared to the US. The method used by IER is very similar to that adopted by BLS. Predictions for the next 10 year period are updated occasionally but usually every three years, with the latest projections compiled by the UK Council for Employment and Skills (UKCES, 2009) in 2008 for the 2007-17 period.

In Australia, the occupational forecasting effort has been underway for more than 20 years and is facilitated by the Department of Education, Employment and Workplace Relations (DEEWR) with the General Equilibrium modelling effort (ie, MONASH model) and the subsequent labour market extensions carried out at Monash University by the Centre of Policy Studies (CoPS). The coverage of both occupations (340) and in particular industries (158) is wide and predictions for the next 5 year period is carried out every year with the latest available for the $2010-15$ period. 
The Canadian occupational projections system (COPS) operated by Human Resources and Skills Development Canada (HRSDC) are for a 10 year period. These are similar to those undertaken in the US and the UK but cover fewer occupations (about 100-150) than in the US and Australia. The latest projections are for 2009-18 (HRSDC, 2009).

The work on constructing a broad occupational forecasting framework in New Zealand commenced in 2006 based on reviews of such methodologies being used abroad (Papps, 2001).

The occupational employment forecasting framework developed for the New Zealand national labour market and some of the preliminary results were presented at the LEW12 (Labour, Employment \& Work) Conference (SriRamaratnam et al, 2006). This was carried out for 25 very broad 2-digit occupational categories but was extended to 96, 3-digit occupational groups in 2007. With the expansion of the industry coverage from 28 (at the National accounts level) to 53 (BERL-CGE model industries) there has been preliminary work undertaken to extend the occupational coverage to about 200.

\section{For How Long Has It Been Done?}

The duration for which occupational forecasting has been practiced in some Developed countries, the scope of occupational and industry coverage, the period of projection and their frequency are summarised below for four other Western countries and for New Zealand:

\section{Country: How Long - How many - Period (How often)}

○ US - over 60 years -530 Occ. X 50 Ind. -10 years period (Biennial)

○

UK - about 30 years - 25 Occ. X 67 Ind. - 10 years (usually every 3 years)

○ Australia - about 30-35 years - 340 X 158 - 5 years (Annual)

- Canada - about 40 years - 139 X $67-10$ years

(Annual updates to different components)

○ New Zealand $-<5$ years -96 X $28-5 \& 10$ years

(Annual -+ ad hoc)

\section{Who Is Doing and Paying For It?}

The agencies responsible for compiling and reporting (as opposed to producing them especially in the case of UK and Australia) the occupational forecast is provided in Table 1 below. With the exception of the projections compiled by DEEWR for Australia (which is for a 5 year period), all are for a 10 year forecast period. However, the latest occupational forecasts available are for slightly different forecast horizons. This is due to the varying base years used from which time periods these projections were carried out ranging from 2008 in the UK to September 2010 in New Zealand.
Table 1: Agencies, latest Occupational forecast periods \& timing

\begin{tabular}{|r|r|r|r|r|r|}
\cline { 2 - 6 } \multicolumn{1}{c|}{} & Australia & Canada & \multicolumn{1}{c|}{ UK } & \multicolumn{1}{c|}{ USA } & \multicolumn{1}{c|}{ NZ } \\
\hline Forecast Source: & & & & & \\
Forecast Periods: & DEER & HRSDC & UKCES & BLS & DoL \\
Forecast made in: & Jul-10 & $2009-18$ & $2007-17$ & $2008-18$ & $2009-19$ \\
\hline
\end{tabular}

\begin{tabular}{|r|r|r|r|r|r|}
\hline $\begin{array}{r}\text { I. Replacement } \\
\text { or Retirement }\end{array}$ & \multicolumn{3}{|l|}{} \\
\hline Forecast Source: & CEET & HRSDC & UKCES & BLS & DoL \\
Forecast Periods: & $2008-13$ & $2004-14$ & $2007-17$ & $2008-18$ & $2006-16$ \\
Forecast made in: & 2009 & late 2005 & 2008 & Dec-09 & 2009 \\
\hline
\end{tabular}

The forecast periods for the expansion demand and the replacement/retirement demand were different for some countries when responsibility is with different agencies (eg in Australia). They can, however, also be different if a single agency is responsible (eg, Canada and New Zealand) due to varying availability of the data sources.

In New Zealand, the 5-yearly census data is used to apply the cohort component method for 5 year age cohorts. Historical estimates for the 1996-2001 and 2001-2006 periods have been used to project the likely retirement and replacement levels for the 2006-11 and 2011-16 forecast periods. In some countries, due to the availability of data from annual job mobility surveys (eg Australia) the estimates are based on annual flows rather than for 5 year inter-census periods such as in New Zealand. In Canada, the data from the Longitudinal Administrative Databank (LAD) was used by HRSDC to econometrically estimate the retirement rates.

In Australia, a number of federal and state training authorities are the subscribers of the work done by CoPS at Monash University and DEEWR is the main facilitator of these forecasts used on their website - "Job Outlook". In the US, the Department of Labour is responsible for the forecasts produced by BLS, the statistical \& analysis arm of the US DoL. In the UK, the Department of Education \& Skills (the UKCES now) is responsible for funding this forecasting activity carried out by IER, a private University of Warwick based research outfit. In Canada, the occupational forecasting and retirement forecasts are undertaken by the HRSDC in-house. In summary, the respective Governments are organising this forecasting activity in-house or paying for this activity.

\section{The Rationale for Skills Forecasting}

The main goal of building the forecasting capability at the Department of Labour was to contribute to its goal of becoming the authority on labour market knowledge. Forecasting labour market outcomes was seen to be of interest to policy formulation and operational decisions (eg, training). It has been argued that the market signals usually occur too late to enable a timely policy response for the often substantial training time-lag associated with producing skilled labour.

An assessment of international trends in occupational forecasting and skills research was undertaken by the Economic Research Unit of Northern Ireland (McGuiness and Bennett, 2008). Having reviewed the practice in some 15 countries they concluded that "in general, policy 
makers in developed economies rely on occupational forecasting models to predict the future direction of skills demand". It was noted that these countries committed considerable effort and resources in forecasting changes in the composition of demand for skilled labour over time as a means of getting a better understanding of the extent of skill shortages within the economy. They also concluded that "such models have become increasingly accurate over time but for occupational forecast to be of value, precision is less important than the ability of the data to be interpreted and made use of by a range of interest groups".

\section{How Is It Being Used?}

The potential benefits of skills forecasts and future labour market insights or intelligence are generally numerous:

(i) From an individual perspective they could reduce the uncertainty associated with educational returns which otherwise might deter human capital investment (eg Job Outlook website maintained by DEEWR in Australia),

(ii) From a firm perspective, they could enable companies to facilitate timely training initiatives that prevent labour market related bottlenecks occurring, but most importantly,

(iii) From the perspective of policy makers and training providers, they assist with information necessary to initiate changes proactively before skills issues emerge.

As substantial benefits potentially accrue to individuals, firms and governments, it was argued that the provision of such labour market information is a public good. The occupational forecast information produced by the Department has been used in New Zealand by both internal and external stakeholders in the following manner:

\section{Internal Stakeholders;}

(a) Immigration service for reviewing and updating the Skills Shortage (Short-term and Long-term) lists for the past 1-2 years since their review along with other relevant historical and recent trends in demand and supply and

(b) Skills analysis at DoL (both Policy \& Operational) where forecasts are combined with other characteristics of occupational employment (see the DoL Skills Insight Tool below).

\section{External Stakeholders;}

This covered a portal for making information available for the general public as well as examples of engagements with specific state sector stakeholders:

(a) Skills Insight Tool - This portal on the DoL website contains occupational forecast information since late 2008 along with other characteristics of occupational employment and historical series.

(b) Skills Gap Analysis - This exercise, which was important for the discussions with the Treasury during 2008 and 2009, was carried out for high level Skill Groups and incorporated forecasts for a longer period (10 years) on the demand side to compare with the supply forecasts by qualifications. (c) MSD \& Work \& Income - regional W\&I staff have received national industry level employment forecasts for the past two years for use in their priority setting (a regional breakdown was carried out in 2010)

(d) MPIA - Occupational and industry employment forecast information produced by DoL were used by MPIA with the aim of identifying industries and occupations the Pacific Peoples should or could be compared to where they are at present.

\section{What More Can It Be Used For?}

In countries where occupational employment forecasts have been produced for a while, their primary use has been in making training decisions at the national and regional levels. In the UK, the Training and Enterprise Councils (TEC) are the major users of such forecasts along with the Department of Education and Skills (DfES) while the Australian National Training Authority (ANTA) along with the 5 state training authorities use them along with DEEWR in Australia.

In New Zealand, there is limited and systematic use of such labour market insights by training authorities and agencies responsible for the allocation of training funds. This is partly due to their particular needs with respect to matching occupational forecasts with qualifications by fields of study in tertiary education or vocational training for skilled trades. This is likely to change over time when the labour market moves from a situation of excess supply to extra demand for a wide range of skills across various industries and sectors. But given the training lags, use of such information in training decisions are critical.

\section{Methodological Approaches Adopted}

The standard or conventional approach to skills forecasting is to utilise macroeconomic models along with an economy-wide or General Equilibrium (GE) model in order to break employment down in terms of industries and also occupations within industries. But some countries have adopted alternative approaches for projecting skills demand which include employer skills surveys, sector studies and qualitative methods on their own and/or to complement the above mentioned quantitative model based approaches.

\section{Macroeconomic / General Equilibrium (Conventional) Top-down Approach}

The key steps in occupational forecasting approaches linked to General Equilibrium (GE) models followed by the US (BLS), UK (IER/UKCES) and Australia (DEEWR/MONASH-CoPS) are very similar although the level of details in terms of occupations varies. The CoPS researchers have noted that for the purpose of policy analysis, forecasts must satisfy four main requirements: detail, transparency, accessibility and reliability. 


\section{Macroeconomic factors \& General Equilibrium models:}

The approaches followed require forecasts of key macroeconomic factors as benchmarks for a Computable General Equilibrium (CGE) model along with the necessary policy mix and assumptions on levels of productivity and technical changes anticipated. This approach is also followed in New Zealand. This is also referred to as generating industry share effects which are subsequently used to for the the labour market extensions listed below. In addition, it is possible to produce alternative macroeconomic projections consistent with competing views of the future.

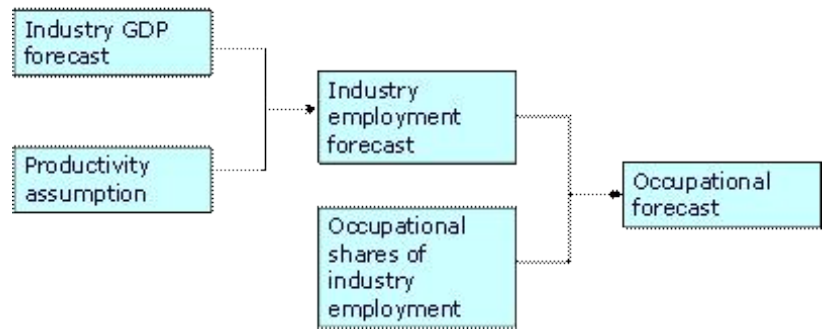

In addition, it would be possible to break national level forecasts of output and employment into regional forecasts taking into account a) regional differences in industrial structures, b) population movements, c) region specific (positive or negative) events or expenditures and d) local or regional multipliers.

\section{Labour market extensions:}

In the first step of labour market extensions, the employment forecasts are converted from an industry basis to an occupational basis (ie, occupational share effects). An industry by occupation employment cross tabulation can derived from the Population Censuses and can be used as the benchmark for a future occupational mix by industry based on historical trends.

In addition, changes in the number of hours worked per worker in an occupation are derived by extrapolating past trends. Factors underlying these trends (in occupational mix and hours worked) could also be identified through analytical studies (eg., econometric or multivariate analysis) of specific industries and occupations in relation to technological change and a wide variety of other economic data.

In the next step, the forecasts for employment by occupation in persons are used to determine the employment outlook in terms of demographic features identified by age, sex, qualifications and hours worked per week. This methodology is similar to that used to determine the occupational forecasts from the industry forecasts. The US approach actually involves the determination of the future size and composition of the labour force by projecting the age, sex, and ethnic composition of the population based on birth rates, death rates and net migration rates along with the trends in labour force participation rates.

\section{Decomposition analysis:}

Interrogating the forecasting system in any combination of features is a key part of the exercise to provide some transparency and validation of outcomes. A variation of shift-share analyses can be carried out whereby employment growth in one category is "explained" or related in terms of employment growth in another category. One such example is an assessment of the contribution by various industries to the growth of tradespersons and related workers. The order of the explanation could also be reversed, i.e. the contribution of the occupation "Tradespersons and related workers" to employment growth in the industry "Construction".

Another potentially useful analysis is the assessment of how much labour in any category (industry, occupation etc) is linked to producing goods and services for different segments of the economy such as intermediate usage, household or government consumption, capital accumulation or international trade which is referred to as "embodied labour calculation".

\section{US Experiences:}

The Bureau of Labor Statistics (BLS) which is a division of the US Department of Labor in the US has a long running occupational forecasting programme. Results from this programme comprise a major component of the Occupational Outlook Handbook which is revised biennially. Published since 1949, the content of the Handbook has changed little but the information provided now is significantly different reflecting improvements in data availability and methodologies using basic procedures adopted in late $70 \mathrm{~s}$.

Occupational employment projections rely on an industryoccupation cross tabulation which represents the distribution of employment over more than 250 industries and 500 occupations. The changes in the number of jobs in a particular occupation is categorised as small $(\sim 10 \%)$, moderate $(\sim 20 \%)$ and significant $(>30 \%)$ and result from changes in the occupational composition of the various sectors and/or the overall shifts in the industrial structure of the economy.

The accuracy of employment projections in the US is considered to be good for broad trends in occupational employment (within 5\%) but the discrepancies between projected \& actual growth rates of detailed occupational groups have remained between $20-25 \%$ over many years. The fastest and slowest growing occupational groups were projected with high level of accuracy.

\section{The Australian Practice:}

In Australia occupational forecasting has been carried out now for about 30-35 years at the Centre of Policy Studies (CoPS) of the Monash University in Melbourne. A dynamic general equilibrium model known as MONASH has been used since the early 1990s. MONASH forecast of the demand for labour consists of a number of steps broadly correspond to those taken by the BLS in producing the US forecasts. 
In Australia, this approach enables projections of employment for 158 industries (according to the ANZSIC-3 digit level) and 340 occupations (according to ANZSCO-4 digit level) along with 8 educational attainment levels and 47 qualification fields (according to ABS Classification of Qualifications). In addition, 24 demographic groups differentiated by age and sex and 9 categories of hours worked per week is also part of the distributional results.

CoPS forecasts are produced in conjunction with CEET (Centre for the Economics of Education \& Training) at Monash University whose role is to project replacement demand $\&$ job turnover by occupations.

\section{The UK Approach:}

In the UK, occupational forecasting has been operationalised using the multi-sectoral dynamic model of the economy (MDM) developed by Cambridge Econometrics $(\mathrm{CE})$. The forecasts are prepared using the latest version of the Cambridge Econometrics Multisectoral Dynamic Model (MDM Revision 900) which is based on the 2003 Standard Industrial Classification (SIC2003). The most recent National Accounts data (with chained volume measures and reference year 2003), along with an input-output table and classification converters, have been incorporated into MDM Revision 900.

A key relationship is that between industry employment and output. To complement the employment equations, a set of hours equations by industry have also been estimated, which relate average weekly hours worked by industry to normal hours and capacity utilisation. The macroeconomic model is, in general, based on econometric analysis of long time series data sets. It is characterised by many feedbacks. By contrast, the other sub-models relating to occupational employment and replacement demands are based on more limited data and do not feed back into the main macroeconomic model. These include the models used to develop projections of occupational structure and qualifications.

\section{Relevant Lessons for New Zealand:}

Occupational forecasting experiences of other countries, especially in the US, the UK and in Australia, suggest that it is beneficial for both policy development and with career guidance. The methodology has been applied and refined over many years now. The informational requirements and processing for maintaining an effective system, let alone setting-up a new system, is resource intensive and the occupational projections have varying degrees of accuracy depending on the level of distributional details and disaggregation considered.

\section{Industry or Sector Studies / Skills Surveys (Variant) Bottom-Up Approach}

The standard top-down approach is the most common in many countries (Australia, US, Canada and UK) and is the conventional approach to occupational forecasting. But reliable macroeconomic and CGE models are often unavailable for use in regional applications where the demand for such forecasts are the greatest and the data required to develop them is also quite difficult to assemble. The labour market extensions used in the conventional approaches which tend to extrapolate the historical trends in occupational and qualification shares is also considered to be deficient in capturing unusual occupational changes in response to consumer demand and new technology.

While the standard forecasting approach could be viewed as "highly" mechanistic with limited ability to be responsive to changing labour market conditions, sector studies and employer surveys are prone to bias arising from sampling and also reporting error in particular when responses exaggerate the demand for skilled labour and/or the extent of skill shortages experienced. The Sectoral studies involve both quantitative and qualitative methodologies in order to form a view of key skill issues within a sector. The ITOs, which come under the umbrella of the ITF in New Zealand, could be considered in the same light.

In the UK, comprehensive National Employer Skills Surveys (NESS) have been undertaken every two years by the Learning and Skills Council (LSC) since 2003 with the latest being in 2009. The results from these surveys are also reported by UKCES and provide specific insights about different types of skill shortages and skill gaps across selected sectors and occupations. Hence they complement the Working Futures reports that include the skills projections, which are also produced periodically, every 2-3 years.

\section{Preferred Combination}

Given the strengths and weaknesses of these two different approaches to skills analysis, it has been suggested that where data and modelling capability permit, standard (top-down) occupational forecasts should be produced regularly complemented by the more qualitative (bottomup) approaches to produce a more rounded and enriched view of changing skill needs.

The development of Sector Skills Councils in the UK (about 25 of them), Sector Councils in Canada (about 35 of them) and Industry Skills Councils in Australia (10 of them since 2003) also provide some opportunity to undertake bottom-up verification of the top-down forecasts. In Australia, the Regional surveys and Industry surveys are also used to verify the model based forecasts. 


\section{What Are The Latest Forecasts Suggesting?}

The main objective of this paper was to provide a useful comparison of the "latest" occupational forecasts by selected Developed country public sector labour market institutions with forecasts for New Zealand generated at DoL. In order to present these results it was important first to provide some background on the state of play, the rationale for skills forecasting as well as the methodology used in different countries.

\section{Underlying Macro-Economic Conditions}

The conventional top-down methodological approach to employment forecasting is based on the underlying macroeconomic conditions and the economy-wide outcomes for the respective countries. Hence in Table 2 the average annual GDP growth underpinning the overall average annual employment growth over the 10 year forecast period is summarised, with the exception of Australia where it is for the next 5 year period.

Table 2: Macroeconomic Factors underlying the Forecasts

\begin{tabular}{|r|r|r|r|r|r|}
\multicolumn{1}{c|}{ Australia } & \multicolumn{1}{c}{ Canada } & \multicolumn{1}{c}{ UK } & \multicolumn{1}{c}{ USA } & \multicolumn{1}{c|}{ NZ } \\
\hline Forecast Periods & $\mathbf{2 0 1 0 - 1 5}$ & $\mathbf{2 0 0 8 - 1 8}$ & $\mathbf{2 0 0 7 - 1 7}$ & $\mathbf{2 0 0 8 - 1 8}$ & $\mathbf{2 0 0 9 - 1 9}$ \\
\cline { 2 - 7 } GDP Growth & $3.4 \%$ & $2.4 \%$ & $2.4 \%$ & $2.8 \%$ & $2.4 \%$ \\
Productivity & $1.6 \%$ & $1.6 \%$ & $1.8 \%$ & $1.8 \%$ & $1.4 \%$ \\
\cline { 2 - 6 } Employment Growth & $\mathbf{1 . 8 \%}$ & $\mathbf{0 . 8 \%}$ & $\mathbf{0 . 6 \%}$ & $\mathbf{1 . 0 \%}$ & $\mathbf{1 . 0 \%}$ \\
\hline
\end{tabular}

The average GDP growth resulting from the economywide models varied between $3.4 \%$ in Australia and about $2.4 \%$ in New Zealand, Canada and also the UK and the growth prospects for USA is forecast at $2.8 \%$ per annum. The overall labour productivity increases underlying the employment growth also varied between $1.8 \%$ in the US and the UK to $1.1 \%$ in New Zealand with productivity growth in Australia and Canada being 1.6\%.

\section{High Level Skill Mix - Expected Directions}

In this section the occupational forecasts for New Zealand and for the comparator countries are summarised into four broad skill groups as illustrated in the table provided below in order to provide comparisons of the levels and the rates of changes (Table 3) and the resulting shares (Table 4) for these broad skill groups. The following skill groups are identified:

\section{Occupational groupings for the four skill groups}

\begin{tabular}{l|l}
\hline Skill group & Occupations Included \\
\hline Highly skilled & Managers and Professionals \\
\hline Skilled & $\begin{array}{l}\text { Associate Professionals, Technicians } \\
\text { and Skilled Trades workers }\end{array}$ \\
\hline Semi-skilled & $\begin{array}{l}\text { Clerical, Sales, Service and Primary } \\
\text { sector workers }\end{array}$ \\
\hline Elementary & $\begin{array}{l}\text { Machinery operators, Drivers and } \\
\text { Labourers }\end{array}$ \\
\hline
\end{tabular}

As reported in Table 2, overall employment growth for all countries is expected to be modest over the ten year forecast period except for Australia where this is about $1.8 \%$ over the next 5 years.

More importantly, the compositional changes by broad skill groups indicate that the Highly Skilled category had the highest growth rates. The latest occupational forecast for Canada was unavailable. The growth rates for this group ranged from between $1.4 \%$ to $1.6 \%$ per annum in most countries, well above the overall employment growth, to about $2.5 \%$ in Australia. At the opposite end of the skill spectrum, the Elementary Skill group is forecast to see small negative growth $(-0.3 \%)$ in the UK, flat growth in the US, modest growth $(0.7 \%)$ in New Zealand and substantial (1.2\%) growth per annum in Australia.

In the case of the medium Skill categories, the SemiSkilled group is forecast to grow somewhat faster than the Skilled group in New Zealand $(0.8 \%$ versus $0.1 \%$ due to the very small positive growth in Skilled trades) and in Australia (1.8\% versus $1.3 \%$ ) while the opposite is true in the case of UK and the US where the Skilled occupations (such as Technicians and Associate Professionals) are expected grow faster than the Semi-skilled occupations (such as sales, service and clerical workers).

The shares for each of the four broad Skill Groups are compared across countries in the base years and also in the forecast years in Table 4. This enables an assessment of the levels and changes in the Skills Mix in each of these countries.

\begin{tabular}{|c|c|c|c|}
\hline New Zealand & 2009 & 2019 & 2009-19 \\
\hline (Source: DoL) & (Estimates) & (Projections) & (Av. Changes/Year) \\
\hline Highly Skilled & 875,065 & $1,010,806$ & $1.5 \%$ \\
\hline Skilled & 270,015 & 273,427 & $0.1 \%$ \\
\hline Semi-Skilled & 652,201 & 707,468 & $0.8 \%$ \\
\hline Elementary & 375,491 & 401,299 & $0.7 \%$ \\
\hline Total & $2,172,773$ & $2,393,000$ & $1.0 \%$ \\
\hline$\overline{\text { USA }}$ & 2008 & 2018 & 2008-18 \\
\hline (Source: BLS) ('000s') & (Estimates) & (Projections) & (Av. Changes/Year) \\
\hline Highly Skilled & 46,800 & 53,691 & $1.4 \%$ \\
\hline Skilled & 43,184 & 48,712 & $1.2 \%$ \\
\hline Semi-Skilled & 40,003 & 42,826 & $0.7 \%$ \\
\hline Elementary & 20,944 & 20,977 & $0.0 \%$ \\
\hline Total & $\overline{150,931}$ & 166,206 & $1.0 \%$ \\
\hline Australia & 2010 & 2015 & $2010-15$ \\
\hline (Source: DEEWR) ('000') & (Estimates) & (Projections) & (Av. Changes/Year) \\
\hline Highly Skilled & 3,609 & 4,082 & $2.5 \%$ \\
\hline Skilled & 1,629 & 1,734 & $1.3 \%$ \\
\hline Semi-Skilled & 3,664 & 4,010 & $1.8 \%$ \\
\hline Elementary & 1,842 & 1,951 & $1.2 \%$ \\
\hline Total & 10,744 & 11,777 & $1.85 \%$ \\
\hline$\overline{\text { UK }}$ & 2007 & 2017 & $2007-17$ \\
\hline (Source: UKCES) ('000') & (Estimates) & (Projections) & (Av. Changes/Year) \\
\hline Highly Skilled & 8,919 & 10,434 & $1.6 \%$ \\
\hline Skilled & 7,876 & 8,304 & $0.5 \%$ \\
\hline Semi-Skilled & 8,615 & 8,766 & $0.2 \%$ \\
\hline Elementary & 5,826 & 5,680 & $-0.3 \%$ \\
\hline Total & 31,236 & 33,184 & $0.6 \%$ \\
\hline
\end{tabular}

The largest category in all four countries is the Highly Skilled group, both in the base years as well as in the forecast years. In the US and in the UK, they made up only about 29-31\% while in Australia and New Zealand this is between $35-40 \%$ in the Base years. But in all cases the Highly Skilled group is expected to grow its share by between $1-2 \%$ in the US and New Zealand and by almost $3 \%$ in the UK and in Australia over the forecast periods. 
Table 4: High Level Skill Mix - Shares

\begin{tabular}{|c|c|c|}
\hline New Zealand & 2009 & 2019 \\
\hline \multicolumn{3}{|l|}{ (Source: DoL) } \\
\hline Highly Skilled & $40.3 \%$ & $42.2 \%$ \\
\hline Skilled & $12.4 \%$ & $11.4 \%$ \\
\hline Semi-Skilled & $30.0 \%$ & $29.6 \%$ \\
\hline Elementary & $17.3 \%$ & $16.8 \%$ \\
\hline Total & $100 \%$ & $100 \%$ \\
\hline$\overline{\text { USA }}$ & 2008 & 2018 \\
\hline \multicolumn{3}{|l|}{ (Source: $B L S$ ) } \\
\hline Highly Skilled & $31.0 \%$ & $32.3 \%$ \\
\hline Skilled & $28.6 \%$ & $29.3 \%$ \\
\hline Semi-Skilled & $26.5 \%$ & $25.8 \%$ \\
\hline Elementary & $13.9 \%$ & $12.6 \%$ \\
\hline Total & $100 \%$ & $100 \%$ \\
\hline Australia & 2010 & 2015 \\
\hline \multicolumn{3}{|l|}{ (Source: DEEWR) } \\
\hline Highly Skilled & $35.0 \%$ & $38.0 \%$ \\
\hline Skilled & $15.0 \%$ & $14.0 \%$ \\
\hline Semi-Skilled & $33.0 \%$ & $32.0 \%$ \\
\hline Elementary & $17.0 \%$ & $16.0 \%$ \\
\hline Total & $100 \%$ & $100 \%$ \\
\hline$\overline{\text { UK }}$ & 2007 & 2017 \\
\hline \multicolumn{3}{|l|}{ (Source: UKCES) } \\
\hline Highly Skilled & $28.6 \%$ & $31.4 \%$ \\
\hline Skilled & $25.2 \%$ & $25.0 \%$ \\
\hline Semi-Skilled & $27.6 \%$ & $26.4 \%$ \\
\hline Elementary & $18.7 \%$ & $17.1 \%$ \\
\hline Total & $100 \%$ & $100 \%$ \\
\hline
\end{tabular}

The shares among the other three broad Skill Groups are very similar in New Zealand and Australia with the SemiSkilled group being the next largest. All these shares are forecast to decline by about $1 \%$ over the forecast periods. But in the US and in the UK the Skilled and Semi-Skilled Groups are of similar size and the Semi-Skilled category forecast to decline by about $1 \%$ over the forecast periods. The Elementary Skill Group is of similar size in all four countries (somewhat smaller in the US) and forecast to decline by between $1-2 \%$ over this period.

\section{Broad Occupational Results -Expected Changes}

The high level information for the four Skills Groups provided in Tables 3 and 4 is disaggregated in Table 5.

\begin{tabular}{|c|c|c|c|c|}
\hline & $\begin{array}{c}\text { New Zealand } \\
(2009-19)\end{array}$ & $\begin{array}{c}\text { USA } \\
(2008-18)\end{array}$ & \begin{tabular}{l|} 
Australia \\
(2010-15)
\end{tabular} & \begin{tabular}{|c|} 
UK \\
$(2007-17)$
\end{tabular} \\
\hline Managers & $1.4 \%$ & $1.0 \%$ & $2.0 \%$ & $1.8 \%$ \\
\hline Professionals & $1.5 \%$ & $1.6 \%$ & $2.6 \%$ & $1.6 \%$ \\
\hline Technicians & $0.1 \%$ & $0.5 \%$ & $1.8 \%$ & $1.5 \%$ \\
\hline Office \& Clerical Workers & $0.2 \%$ & $0.7 \%$ & $1.2 \%$ & $-1.1 \%$ \\
\hline Sales Workers & $0.8 \%$ & $0.6 \%$ & $1.4 \%$ & $0.4 \%$ \\
\hline Service Workers & $1.7 \%$ & $1.3 \%$ & $3.1 \%$ & $1.8 \%$ \\
\hline Trades Workers & $0.1 \%$ & $1.0 \%$ & $1.3 \%$ & $-0.7 \%$ \\
\hline Drivers and Plant \& Machinery Operators & $0.9 \%$ & $0.4 \%$ & $1.4 \%$ & $-0.5 \%$ \\
\hline Elementary Workers \& Labourers & $0.6 \%$ & $-0.4 \%$ & $1.0 \%$ & $-0.1 \%$ \\
\hline Total & $1.0 \%$ & $1.0 \%$ & $1.8 \%$ & $\overline{0.6 \%}$ \\
\hline
\end{tabular}

The forecast changes for the 1-digit occupational groups indicate that employment levels of both Managers and Professionals (who make up the Highly Skilled Group) are expected to rise consistently across all countries. The growth in the Professional employment is $1.5 \%$ per annum in all countries or higher and somewhat higher than for the Mangers in the US and in Australia.

The employment levels of Technicians and those who are Trades workers (making up the Skilled group) is forecast to grow very little in New Zealand but is appreciable in Australia. In the US, the number of Technicians is expected to rise very little and in the UK the Trades workers are actually forecast to decline.

Amongst the occupations in the Semi-Skilled Group, the employment of Service workers is forecast to rise almost as much as the Professional occupations by between 3\% in Australia and $1-2 \%$ per annum in other countries. The employment of Office \& Clerical workers is forecast to increase by between $0.2 \%$ in New Zealand and $1.2 \%$ per annum in Australia but decline in the UK by $1.1 \%$. Employment of Sales workers on the other hand rises in all countries by between $0.4 \%$ (UK) and $1.4 \%$ per annum (Australia) but by $0.6-0.8 \%$ in the US and New Zealand.

Employment in lower skilled occupations such as Drivers and Plant \& Machinery Operators as well as Labourers is forecast to rise in New Zealand and in Australia by between $0.5 \%$ and $1.5 \%$ per annum but is forecast to decline in the UK and in the US, in the case of Labourers.

\section{Broad Sector Results - Expected Changes}

In this section forecast employment changes for broad sector groups for New Zealand and the other countries is provided (see Table 6). Employment in the Primary sector (including Mining) and the Utilities is forecast to grow by between $0.6 \%$ in Canada and $2 \%$ in Australia per annum and by about $1.6 \%$ in New Zealand. But employment in the Primary sector \& Utilities is forecast to decline in the UK $(-2.3 \%)$ and also in the US (-0.4\%).

\begin{tabular}{|c|c|c|c|c|c|}
\hline & $\begin{array}{c}\text { New Zealand } \\
(2009-19)\end{array}$ & \begin{tabular}{|c|} 
Canada \\
$(2008-18)$ \\
\end{tabular} & \begin{tabular}{|l|} 
Australia \\
$(2010-15)$
\end{tabular} & \begin{tabular}{|c|} 
USA \\
$(2008-18)$ \\
\end{tabular} & \begin{tabular}{|c|} 
UK \\
$(2007-17)$ \\
\end{tabular} \\
\hline Primary Sector \& Utilities & $1.6 \%$ & $0.6 \%$ & $2.0 \%$ & $-0.4 \%$ & $-2.3 \%$ \\
\hline Manufacturing & $0.4 \%$ & $0.0 \%$ & $-0.4 \%$ & $-0.9 \%$ & $-1.4 \%$ \\
\hline Construction & $0.4 \%$ & $1.0 \%$ & $2.4 \%$ & $1.7 \%$ & $0.8 \%$ \\
\hline Distribution \& Transport & $1.0 \%$ & $1.0 \%$ & $1.8 \%$ & $0.9 \%$ & $0.6 \%$ \\
\hline Business \& Other (Private) Services & $1.1 \%$ & $1.0 \%$ & $2.3 \%$ & $1.1 \%$ & $1.4 \%$ \\
\hline Non-Market (Public) Services & $1.1 \%$ & $1.0 \%$ & $2.7 \%$ & $1.6 \%$ & $0.6 \%$ \\
\hline & $1.0 \%$ & $0.8 \%$ & $1.85 \%$ & $1.0 \%$ & $0.6 \%$ \\
\hline
\end{tabular}

Employment level in the Manufacturing sector is forecast to decline in most countries, by between $-1.4 \%$ per annum in the UK and $-0.4 \%$ in Australia. It is expected to remain relatively unchanged in Canada and grow slightly by $0.4 \%$ in New Zealand, concentrated in selected industries such as food and beverage, metal products, machinery and equipment manufacturing.

Employment in the Construction sector is expected to grow in all countries, ranging from $0.4 \%$ per annum in New Zealand to $2.4 \%$ in Australia. This is also the case with employment in the Distribution \& Transport 
industries with growth ranging from $1.8 \%$ per annum in Australia to $0.6 \%$ in the UK, while the growth in New Zealand is expected to be $1.0 \%$ per annum.

Among the Service industries, employment is forecast to grow in all countries both in the Private (Business \& Other) and Public (Non-Market) sector activities. Growth is somewhat higher in the Public sector services compared to Private services in most countries with UK being the exception where Public sector employment growth is forecast at a modest $0.6 \%$. Consistent with the higher overall employment growth for the medium term forecast in Australia, employment in both Private and Public sector services is forecast to grow by about $2.5 \%$ per annum.

\section{Expansion Needs versus Retirement Demand}

One of the sub-objective of this paper, was to distinguish employment demand arising from Retirement (an important component of Replacement demand) from that due to Expansion discussed so far. In Table 7 the total flow of employment opportunities forecast is differentiated into those arising from expansion or growth in positions and retirement of existing workers and other replacement due to migration, mortality, mobility between occupational groups etc.

For most countries reviewed here, the expansion component is expected to range from $14 \%$ in the UK to $30 \%$ in the US. The share of the Expansion component is estimated to be about $26 \%$ in New Zealand and Canada.

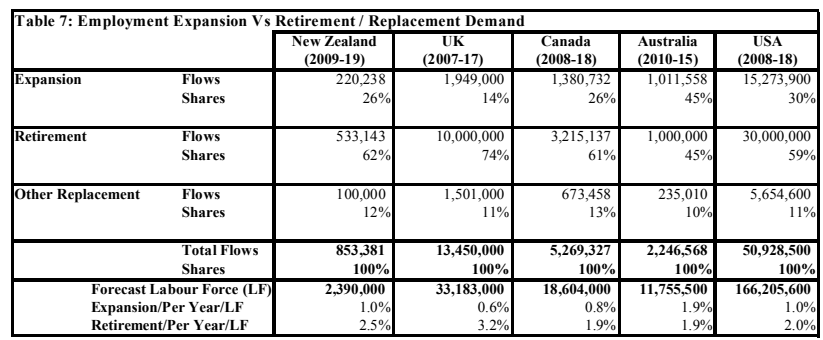

The exception to this is Australia where the share of expansion component is about $45 \%$ and equal to the retirement share due to higher expected economic growth. Conversely, the retirement component ranged from about $60 \%$ in the US, Canada and also New Zealand to more than $70 \%$ in the UK as the labour force in all these countries age and economic growth is forecasted to be low and continuing growth in labour productivity. The other replacement component, excluding retirement, is expected to account for about $10-13 \%$ in all countries.

In order to facilitate an easier comparison across countries with significantly different size of their respective labour force and also shorter forecast period for Australia, annual expansion and retirement flows were derived as ratios of the projected labour force. The respective figures suggest that replacements due to retirement will account for the same as expansion demand in Australia but at least twice as much in the US, Canada and New Zealand and five times as much in the UK.

Table 8: Employment Expansion Vs Retirement / Replacement Demand by Broad Occupational Groups

\begin{tabular}{|c|c|c|c|c|c|c|c|c|c|c|}
\hline \multirow[t]{2}{*}{ Major Occupational groups } & \multicolumn{2}{|c|}{ New Zealand (2009-19) } & \multicolumn{2}{|c|}{ UK (2007-17) } & \multicolumn{2}{|c|}{ Australia (2010-15) } & \multicolumn{2}{|c|}{ USA (2008-18) } & \multicolumn{2}{|c|}{ Average for all countries } \\
\hline & Expansion & Retire/Replace & Expansion & Retire/Replace & Expansion & Retire/Replace & Expansion & Retire/Replace & Expansion & Retire/Replace \\
\hline I. Managers & $41 \%$ & $59 \%$ & $27 \%$ & $73 \%$ & $57 \%$ & $43 \%$ & $30 \%$ & $70 \%$ & $39 \%$ & $61 \%$ \\
\hline II. Professionals & $36 \%$ & $64 \%$ & $31 \%$ & $69 \%$ & $69 \%$ & $31 \%$ & $44 \%$ & $56 \%$ & $45 \%$ & $55 \%$ \\
\hline III. Technicians / Associate professionals & $36 \%$ & $64 \%$ & $41 \%$ & $59 \%$ & $61 \%$ & $39 \%$ & $25 \%$ & $75 \%$ & $41 \%$ & $59 \%$ \\
\hline IV. Skilled Trades & $0 \%$ & $100 \%$ & $-15 \%$ & $115 \%$ & $41 \%$ & $59 \%$ & $35 \%$ & $65 \%$ & $15 \%$ & $85 \%$ \\
\hline V. Service Workers & $44 \%$ & $56 \%$ & $29 \%$ & $71 \%$ & $56 \%$ & $44 \%$ & $40 \%$ & $60 \%$ & $42 \%$ & $58 \%$ \\
\hline VI. Sales Workers & $15 \%$ & $85 \%$ & $25 \%$ & $75 \%$ & $18 \%$ & $82 \%$ & $17 \%$ & $83 \%$ & $19 \%$ & $81 \%$ \\
\hline VII. Office \& Clerical Workers & $5 \%$ & $95 \%$ & $-27 \%$ & $127 \%$ & $42 \%$ & $58 \%$ & $25 \%$ & $75 \%$ & $11 \%$ & $89 \%$ \\
\hline VIII. Drivers \& Machinery Operators & $27 \%$ & $73 \%$ & $31 \%$ & $69 \%$ & $53 \%$ & $47 \%$ & $25 \%$ & $75 \%$ & $34 \%$ & $66 \%$ \\
\hline IX. Elementary workers \& Labourers & $10 \%$ & $90 \%$ & $-50 \%$ & $150 \%$ & $25 \%$ & $75 \%$ & $-10 \%$ & $110 \%$ & $-6 \%$ & $106 \%$ \\
\hline Overall - Average & $25 \%$ & $75 \%$ & $15 \%$ & $85 \%$ & $45 \%$ & $55 \%$ & $30 \%$ & $70 \%$ & $29 \%$ & $71 \%$ \\
\hline
\end{tabular}

The expansion and retirement/replacement shares are also considered here for broad occupational groups (see Table 8) and help to understand the compositional differences of the overall changes reported in Table 7. For occupational groups where the expansion demand is forecast to be negative (eg, Skilled Trades and Office \& Clerical workers in the UK) the Retirement/Replacement makes up for this and will have value higher than $100 \%$. This can be seen in the case of Elementary workers and Labourers in the UK and the USA and hence as average of $106 \%$ for Retirement/Replacement for all countries.
In the case of Managerial occupations, the share of new hires resulting from expansion is about $40 \%$ in New Zealand which is higher than in the UK $(27 \%)$ and the US $(30 \%)$ but less than in Australia (57\%) where employment growth is expected to be stronger. In Professional occupations, the expansion share is slightly less than for Managers in New Zealand at 35\%. This is higher than in the UK but lower than for the US. Again it is almost $70 \%$ in Australia. The average for all countries included in Table 8 is $39 \%$ for Managers and $45 \%$ for Professionals, not dissimilar to the values for New Zealand of $41 \%$ and $36 \%$ respectively. 
For Technicians and Associate Professionals, the share of expansion at $36 \%$ is only slightly lower than the average for all countries (41\%) compared with Australia (61\%) above and USA (25\%) below average. The expansion share of Skilled Trades is about zero in New Zealand and negative $(-15 \%)$ in the UK but is about $35-40 \%$ in the US and Australia with an average of $1.5 \%$.

In the case of Service workers, the share of Expansion in New Zealand at $44 \%$ is very similar to the average for all countries (42\%) compared with Australia (56\%) above and the UK (29\%) below average and the US (40\%) close to the average. In contrast, for Sales workers the share of expansion in overall hire in New Zealand is only $15 \%$ and is somewhat similar to the average (19\%). Similar patterns relative to the average are reported for Australia $(18 \%)$ and the US $(17 \%)$ but they are higher in the UK $(25 \%)$.

For Office \& Clerical workers, the share of expansion growth in New Zealand is 5\%, less than the average across all countries (11\%) as it is much higher in Australia (42\%) and in the US (25\%) although it is negative $(-27 \%)$ in the UK. In the case of Drivers \& Machinery Operators the expansion share of new hires in New Zealand at $27 \%$ is lower than the average across all countries $(34 \%)$ but is similar to that in the US $(25 \%)$. The share of expansion growth for Drivers \& Operators is higher in Australia (53\%) and the UK (31\%).

In the case of Elementary workers \& Labourers, the share of expansion growth in New Zealand is only $10 \%$ but is negative in the UK $(-50 \%)$ and is also the US $(-10 \%)$ but is higher (25\%) in Australia. Overall the results for New Zealand are not dissimilar to the averages across the four countries.

\section{Conclusions}

The motivation for this paper was to review the latest available occupational forecasts for a number of Developed countries as New Zealand is a relative new comer to this area of labour market analysis. In doing that it is important to provide the background on the scope, coverage, rationale as well as details around the methodological approach followed by New Zealand in relation to these countries.

An important objective was also to understand the relative importance of new hires from employment growth in relation to replacement of existing staff due to retirement, migration, mortality, mobility across occupational groups etc. Some of these results for New Zealand, which indicate the growing importance of Retirement/Replacement demand compared to Expansion, have been reported previously (SriRamaratnam et al, 2009) but are compared herewith those for other countries.

Some of the bias towards Retirement and Replacement demand seen in these results could be attributable to the recent recession associated with global financial crisis.
The results of the comparison suggest that Australia is not affected to the same extent as the US, the UK, Canada and New Zealand. However, across all countries the effect of the ageing of the workforce is clearly visible.

\section{Notes}

1. Detailed occupational forecasts were not available for Canada for their inclusion in Tables 3, 4, 5 \& 8.

2. The results for other countries reported are based on latest forecast updates for Australia received from DEEWR and for the US from BLS along with forecasts reported by UKCES for the UK on their website and by HRSDC for Canada.

\section{References}

Alberta's Occupational Demand and Supply Outlook, 2009-2019, (2010). Alberta Employment and Immigration (E\&I), Government of Alberta.

Bureau of Labour Statistics (BLS), (2004) Estimating Occupational Replacement Needs: Historical Needs (1997-2002) and Forecasts (2004-14).

Department for Employment and Learning, (2006). Occupation Forecasts and Replacement demand Analysis for Northern Ireland 2005-2015, Regional Forecasts Limited for the Department for Employment and Learning, Northern Ireland.

Department of Education, Employment and Workplace Relations, (2010). Australian Jobs 2010 (includes Job prospects over the 2010-15 period), DEEWR, Canberra.

European Centre for the Development of Vocational Training (CEDEFOP) (2008) Mind the Gap: Europe's Potential Skills Deficit, Future Skill Needs in Europe, Medium-term Forecast, Luxembourg.

Franklin, J., C., (2007), Employment Outlook: 2006-16, An overview of BLS projections to 2016, Division of Industry Employment projections, Office of Occupational Statistics and Employment Projections (OOSEP), BLS, Department of Labour, Washington DC.

Human Resources and Skills Development Canada, (2006). Estimating and Forecasting Aggregate Retirement Flows in the Canadian Labour Market, Policy Research Directorate, Strategic Policy \& Research Branch, Government of Canada.

Human Resources and Skills Development Canada, (2009). 10-Year Outlook for the Canadian Labour Market (2009-2018), Presentation for Danish Study Group, Policy Research Directorate, Strategic Policy \& Research Branch, Canada. 
Lapointe, M., Dunn, K., Tremblay-Cote, N., Bergeron, L-P, and Ignaczak, L. (2006). Looking-Ahead: A 10-Year Outlook for the Canadian Labour Market (2006-2015), Human Resources and Skills Development Canada, Government of Canada.

McGuiness, S. and Bennett, J. (2008). An Assessment of International Trends in Occupational Forecasting and Skills Research: How Does Northern Ireland Compare? Priority Skills Unit, The Economic Research Unit of Northern Ireland (ERINI) for the Department for Employment and Learning, Northern Ireland.

Neville, I. (2009). Industry and Occupation Employment Change during times of change, Labour Supply \& Skills Branch, Department of Employment, Education and Workplace Relations (DEEWR), Government of Australia.

Papps, K., L., (2001). Occupational and Skill Forecasting: A Survey of Overseas Approaches with Applications to New Zealand, New Zealand Department of Labour Occasional Paper Series, 2001/1, Labour Market Policy Group, Department of Labour.

Shah, C. (1998). Forecasting Occupational Replacement Demand, Centre for the Economics of Education and Training (CEET), Monash University-ACER, for the Department of Employment, Workplace Relations and Small Business, Government of Australia.

SriRamaratnam R., Zhang K., and Whiteford, A. (2006). Forecasting in the Labour Market, presentation at the Labour Market, Employment and Work (LEW) conference, Wellington.

SriRamaratnam R., Zhao X., and Manning, R. (2009). Skills in Demand: Past, Present \& in the Future, presentation at the New Zealand Vocational Education Training (VET) Research Forum, organised by Industry Training Federation (ITF), Wellington.

UK Commission for Employment and Skills (UKCES). (2009), Ambition 2020: World Class Skills and Jobs for the UK, The 2009 Report.

UK Commission for Employment and Skills (UKCES). (2009), Skill for Jobs: Today and Tomorrow, The National Strategic Skills Audit for England 2010, Volume 1: Key Findings, Institute for Employment Studies.

Wilson, R. and Homenidou, K. (2008). UK Commission for Employment and Skills (UKCES), Working Futures 2007-2017, Technical Report on Sources and Methods, Institute for Employment Research, University of Warwick.

Woods, R., A., (2009). Industry Output and Employment Projections to 2018, Employment Outlook: 2008-
2018, Monthly Labor Review, Bureau of Labor Statistics, November. 